\title{
Above and below ground interactions in agroforestry systems
}

\author{
C.K. Ong", J.E. Corlett', R.P. Singh" and C.R. Black"

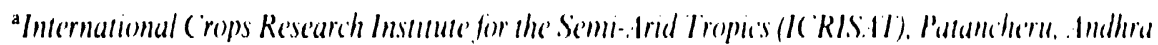 \\ Prodesh 502.324. India

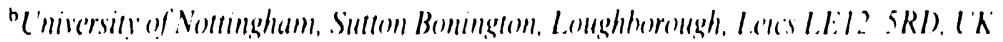

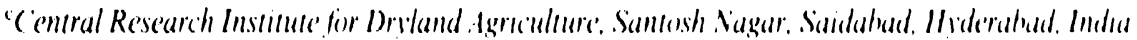

\begin{abstract}
ABSTRAC'T
Ong, C.K., Corlet1, J.E., Singh, R.P. and Black, C.R., 1991. Above and below ground interactions in agroforestry systems. For. Licol. Mlanage'., 45: 45-57.
\end{abstract}

Ecological interactions between trees and crops are examined in terms of above and below ground utilizations of physical resources. Above ground interactions such as changes in light, temperature, and humidity are analyzed in terms of possible effects on understory crops. ( )ur analysis shows that atmospheric interactions in alley cropping in the semi-arid tropics are positive but of minor inportance compared with below ground interactions.

Separation of below ground interactions by a shallow polythene barrier $(0.5 \mathrm{~m})$ indicalced that competition for soil moisture is responsible for the negative interactions reported in the semi-arid

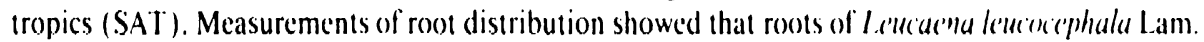
trees are abundant in the top $30 \mathrm{~cm}$ of the soil and the presence of a root barrier was effective in restricting lateral movement of the roots. This evidence is contrary to the assumption that trees have deep rooting systems which do not compete with crops.

A secondary aim is to illustrate the contrasting problems encountered in intercropping and agroforestry systems. The importance or root studies are highlighted and the ways in which positive interactions could be achieved are investigated.

\section{INTRODUCTION}

According to most recent literature, ecological interactions between trees and crops are beneficial for three major reasons. First (and most important), leguminous trees have a beneficial effect on soil fertility through nitrogen fixation, greater organic matter production, and recycling of nutrients (Young, 1986). Second, a combination of annual crops and trees raises biomass production because differences in rooting depth enable uptake of more water and nutrients (Huxley, 1983). Third, the presence of trees acts as a protective barrier against soil erosion or as windbreaks (Wiersum, 1984). There is little 
doubt that when agroforestry systems are designed and managed specifically for maintenance of soil fertility [e.g., alley cropping in Nigeria (Kang et al., 1987) ] or for use as windbreaks for reducing wind damage (e.g., in the Majjia Valley, Niger), the benefits greatly outweigh the negative effects resulting from competition between trees and crops. Aside from these situations, the advantage of tree/crop interaction is less obvious and is poorly documented.

In much of the semi-arid and arid tropics, virtually all crop residue and organic matter are consumed by livestock (Sandford, 1989), and tree prunings are too valuable as fodder to be used as mulch (Singh et al., 1986). Therefore, there appears to be little prospect of appreciable advantages from tree/crop interactions via soil fertility or environmental protection. Hence, under such conditions the major benefit should be obtained from a greater utilization of physical resources. In conventional intercropping (i.e. mixture of two or more crop species ), the evidence for improved utilization of physical resources is well documented; it is also the physiological basis for the higher productivity of intercropping (Marshall and Willey, 1983; Natarajan and Willey, 1980). In a series of detailed studies, Willey and his co-workers at ICRISAT revealed that the benefit is more the result of improvement of above ground interactions (such as greater utilization of radiation) than to better utilization of water or nutrients (Willey and Reddy, 1981).

Above-ground or atmospheric interactions include changes in the microclimate, such as shading, temperature, windspeed and humidity (Monteith et al., 1991). While it is relatively easy to measure the physical variables, interpreting how these changes influence understory crops is quite complex (Cor-. lett et al., 1987). Possible below-ground interactions include greater exploration for water and nutrients and competition for water and nutrients. Experience with conventional intercropping has shown that a separation of the two root systems (i.e. by a polythene barrier) is a simple and effective method of evaluating the relative importance of above and below ground interactions (Willey and Reddy, 1981 ).

The objective of this paper is to examine the evidence for interactions for physical resources between trees and crops, and to determine the relative importance of above and below-ground interactions in situations where leaf mulch or litter is unavailable. Evidence is drawn largely from ICRISAT's work on both conventional cropping and alley cropping because of the scarcity of field data elsewhere. A second aim of this paper is to illustrate the contrasting problems encountered in intercropping and agroforestry situations.

\section{AGROFORESTRY AND INTERCROPPING}

It is widely accepted that the basic concepts of intercropping can be usefully extended to agroforestry systems where information is very limited (Willey et al., 1987). A common objective of both systems is to start crop growth as 
early as possible when the rains begin and to prolong the growing period for as long as possible. For example, on Alfisols in the Deccan Plateau of India, there is often more than adequate moisture to support one crop but insufficient to produce two. In this region, the traditional practice of intercropping sorghum with pigeonpea is an effective way of increasing cropping intensity. The question is: if the pigeonpea in the intercrop is replaced by a tree species such as Leucaena leucocephala Lam., would there be a further extension of the growing season?

Experiments at ICRISAT and elsewhere indicate that $L$. le'ucocephala growth continues throughout the year, producing 2 to $5 \mathrm{tha}^{-1}$ ( 1 tonne $=1 \mathrm{Mg}=10^{3}$ $\mathrm{kg}$ ) of fodder during the dry season when cropping is impossible (Ong. 1991). During a continuous period of 5 years (1984-88), the annual cropping systems on Alfisols produced a total dry matter of $21.4 \mathrm{t} \mathrm{ha}^{-1}$. compared to $32 \mathrm{t}$ $\mathrm{ha}^{-1}$ in the $L$. leucocephala agroforestry system. It is clear that in situations where the physical resources are not fully utilized by crops a combination of trees and crops can greatly increase the total biomass production (a) by taking up more moisture from the soil profile, and (b) by using off-scason rainfall $(20-30 \%$ of the annual rainfall ). It is worth mentioning that during the same period a sole $L$. leucocephala treatment equaled the biomass production of the agroforestry combination and dry-season production exceeded the agroforestry treatment by $20-37 \%$. Thus, if the primary objective is to produce dry-season fodder, it would be advantageous to grow -L. leucocephala as a pure stand.

The concept of land equivalent ratio (LER) is widely used to express the advantage of intercropping over sole cropping. It is defined as the relative land area under a sole crop required to produce the yield obtained in intercropping (Willey, 1979). The advantage of LER is that it assesses the biological efficiency of intercropping.

Values greater than 1 indicate that the intercropping system is more productive or advantageous than sole cropping. For example, the sorghum/pigeonpea intercropping system gave an LER of 1.4 for total biomass, and 1.5 for grain yield (Willey et al., 1987). A similar calculation of LER for the above L. leucocephala agroforestry system on an Alfisol gave a value of 1 for total biomass, but crop yield was reduced by $30-90 \%$ (Singh et al., 1986). Therefore, unlike the intercropping comparison, there appears to be a surprising lack of advantage to the L. leucocephala system in terms of LER. The next step is to examine the underlying mechanisms responsible for the contrasting responses.

\section{MECHANISMS FOR ABOVE-GROUND INTERACTIONS}

In intercropping, the most common mechanism for higher productivity is the 'temporal' sharing of physical resources [i.e. using species of different 
durations so that they demand resources at different times during the season (Willey et al., 1987) ]. For instance, intercropping a fast growing sorghum of $90 \mathrm{~d}$ duration with a slow-growing pigeonpea which matures in $170 \mathrm{~d}$ is a temporal system which minimizes competition (Fig. 1). Light interception by the two canopies revealed that sole pigeonpea was unable to utilize fully the incident light during the first two months of the growing season. In contrast, sole sorghum and intercrop were equally efficient and utilized $52 \%$ of the total light during the first $90 \mathrm{~d}$, compared to $22 \%$ by sole pigeonpea. It is also desirable to have a large difference in the maturity of the two crop species to magnify temporal difference. According to this concept, the combined $L$. leucocephala and sorghum represent an ideal 'temporal' system. A major difference between intercropping and agroforestry occurs at the onset of the rainy season since in intercropping, both species are sown together so that competition for resources builds up gradually, while in agroforestry the L. leucocephala develops a well established root system and a rapidly developing canopy by the second year. In such a situation, the adverse effect of competition

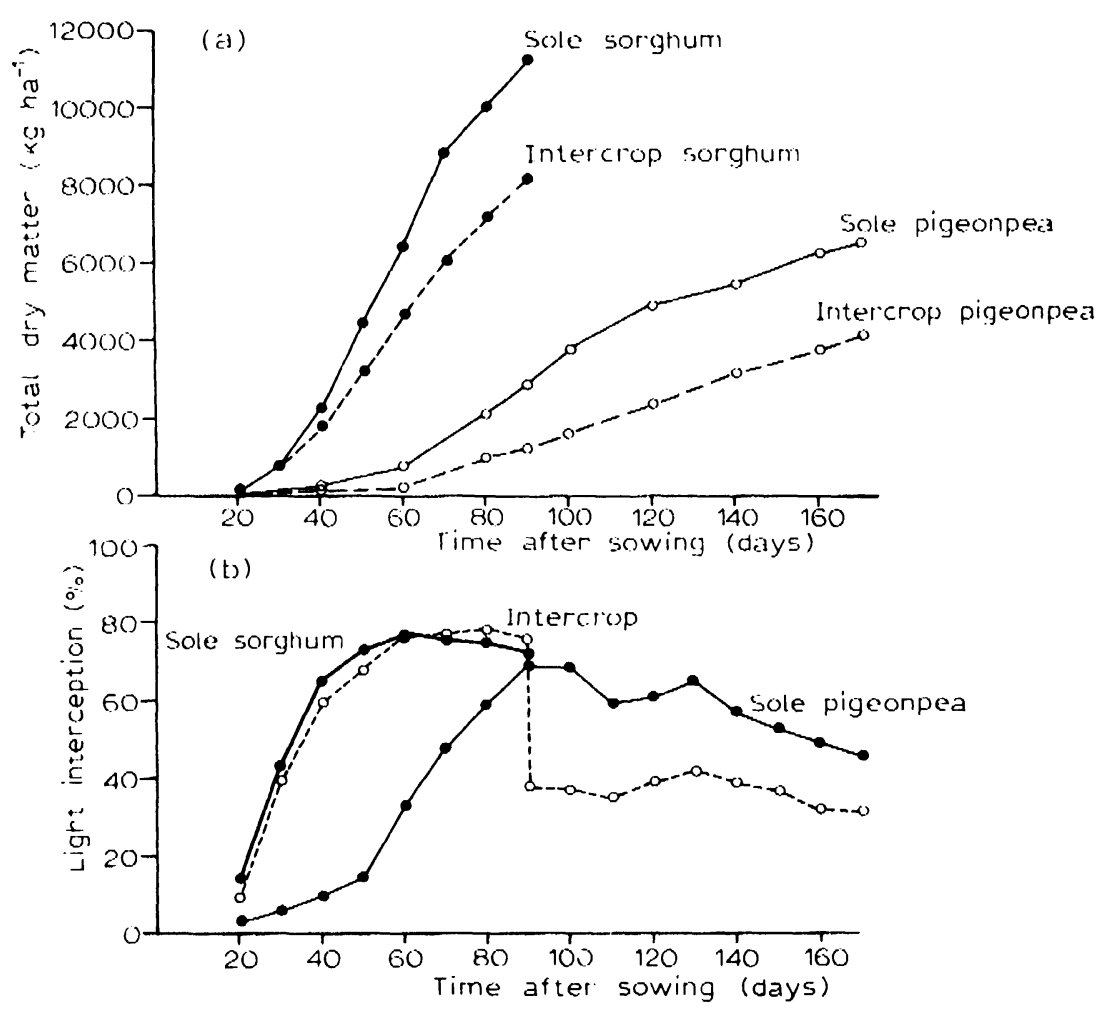

Fig. 1. Dry-matter accumulation (a) and light-interception (b) patterns for sorghum and pigconpea grown in sole and inter-crop systems on Alfisols at ICRISAT Center (Willey et al., 19871 
greatly outweighs the benefit from temporal differences in development and growth.

- Another mechanism for increasing biomass production is the improvement in the photosynthesis of a mixed canopy, generally expressed as the dry matter produced per unit of radiation intercepted (e). For instance, a combination of one row of millet to three rows of groundnut resulted in a $28 \%$ increase in biomass, which was largely explained by a $27 \%$ improvement in ' (Marshall and Willey, 1980). This is possible because the $C_{3}$ groundnut is tolerant of shading of even up to $50 \%$ full light (Stirling. 1988). Thus, unless the understory crops are shade-tolerant $C_{3}$ species, it is unlikely that agroforestry systems would enhance e. Curiously, a major emphasis of agroforestry research is to select mainly $C_{4}$ crop species, which compete successfully with trees. It is possible that improved photosynthetic efficiency may arise from the better dispersion of light within the whole canopy, which is a major advantage of multi-story systems in the humid tropics (Nelliat et al., 1974).

A third kind of positive interaction, which is often attributed to agroforestry, is the amelioration of microclimate ( such as changes in temperature, humidity, or wind speed) (Huxley, 1983). Most agroforestry studies are confined to shelter-belt plantings, and only recently has evidence of amclioration of microclimate from alley cropping in the semi-arid tropics come to light. In the first report on microclimate modification in alley cropping, Corlett et al. (1987) used the thermal time concept to account for temperature effects on plant development. They concluded that the effect was small, amounting to only $21^{\circ} \mathrm{C}$ d over a 50-d period, or a delay in development of $2 \mathrm{~d}$ (Table 1 ). A similar finding was reported for the effect of changes in saturation deficit on millet growth. In their summary, Corlett et al. (1987) suggested that microclimate modification would be more pronounced if $L$. leucocephala hedges

\section{TABLE I}

Ten-day means for daytime leaf temperature and accumulated thermal time in sole millet and alley crop millet, ICRISAT (cnter, rainy season 1986 (Corletl et al.. 1987)

\begin{tabular}{llllll}
\hline Days after sowing & \multicolumn{2}{l}{ Daytime canopy temperature $(c)$} & & Thermal time ( $(\mathrm{d})$ \\
\cline { 2 - 3 } & Sole millet & Alley millet & & Sole millet & Alley millet \\
\hline $21-30$ & 24.0 & 24.4 & 125 & 129 \\
$31-40$ & 26.3 & 26.3 & & 134 & 135 \\
$41-50$ & 23.1 & 23.2 & & 115 & 118 \\
$51-60$ & 24.8 & 24.5 & & 122 & 123 \\
$61-70$ & 27.3 & 26.3 & & 133 & 129 \\
$71-80$ & 25.7 & 24.8 & & 128 & 123 \\
\hline
\end{tabular}


were allowed to grow higher during the rainy season, but because competition for water would also increase, concurrent improvement in light or water-use efficiency would probably not be sufficiently compensated.

\section{MECHANISMS FOR BELOW-GROUND INTERACTIONS}

It is often claimed that a combination of a deep rooting species and a shallow rooting species would provide a 'spatial' sharing of below-ground resources, resulting in a greater utilization of resources. Other potential benefits of below ground interactions in agroforestry systems include nitrogen transfer from nitrogen-fixing trees and improvement of soil physical characteristics. Adverse effects of below-ground interactions (which are rarely mentioned), may result from competition for water, allelopathy, or pest buildup. Few attempts have been made to separate the effects of above- and below-ground interactions in both intercropping and agroforestry systems. However, a field technique to separate below-ground interactions in a millet/groundnut intercrop was described by Willey and Reddy (1981). A trench was dug to $1 \mathrm{~m}$ depth and lined on both with a thick polythene sheet before the crops were sown. The study's results indicated that yicld advantage of intercropping re-

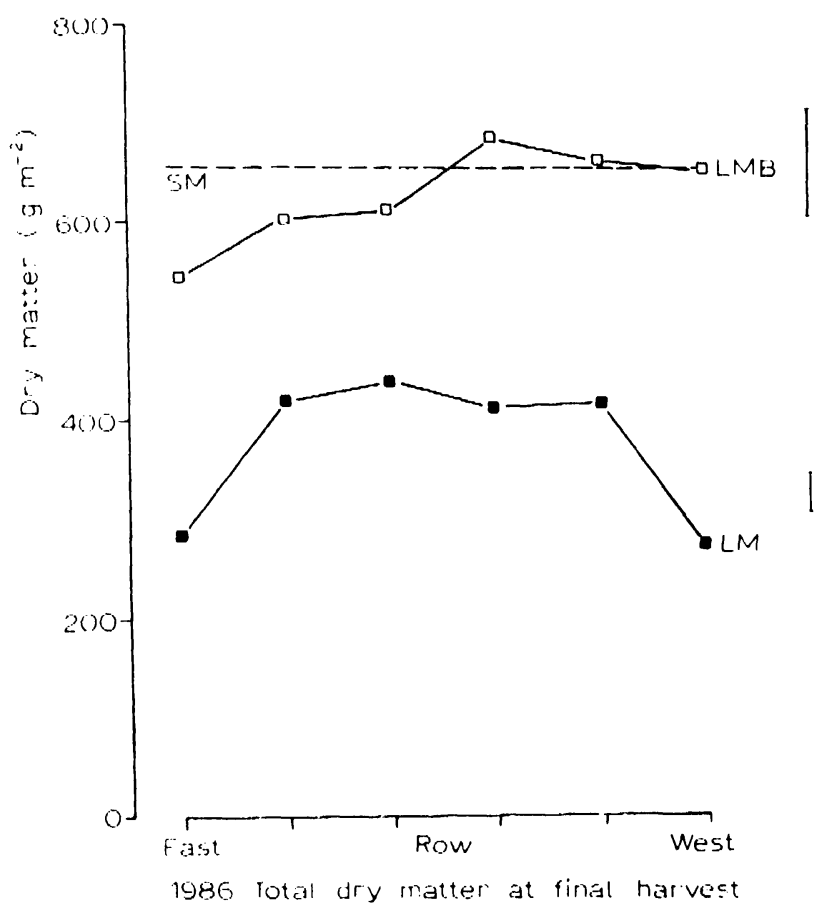

Fig. 2. Total above-ground dry matter accumulated at final harvest in 1986 by pearl millet without an alley crop (width $3.3 \mathrm{~m}$ ) with root barrier ( LMB), the control alley crop (LM) and sole millet (SM). ICRISAT Center, India. Vertical bars are double standard errors (Corlett, 1989). 


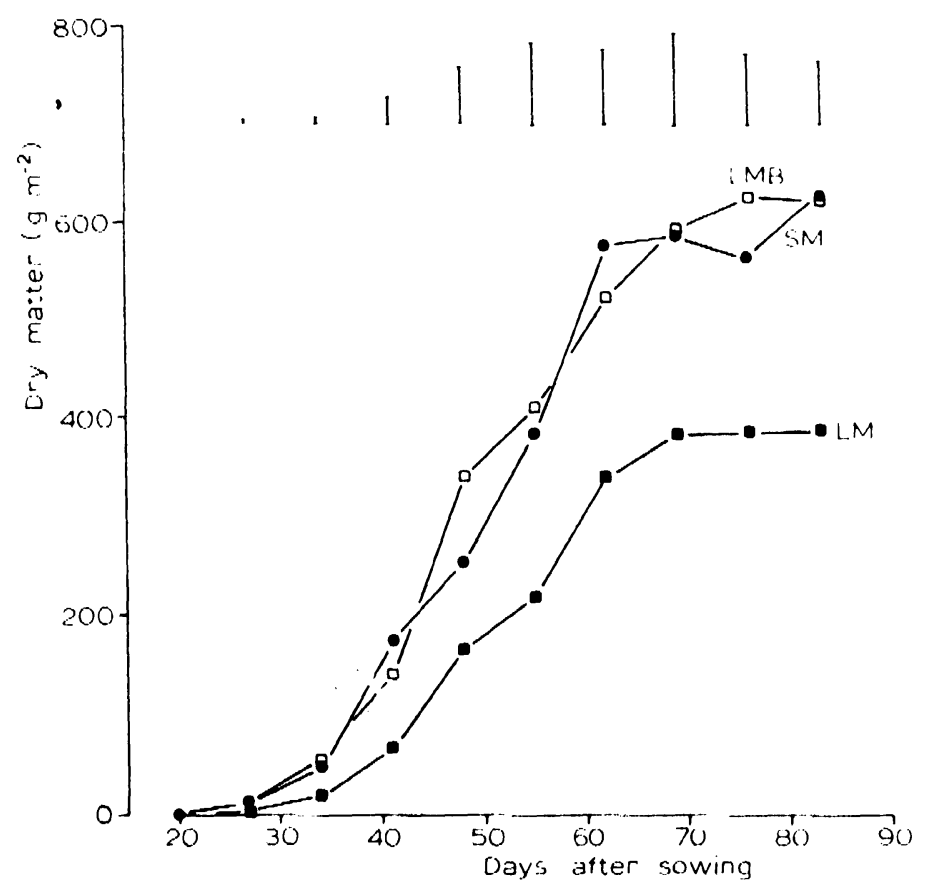

Fig. 3. Seasonal trends of dry-matter accumulation of pearl millet in 1986 in sole millet (SM). the alley crop with root barrier (LMB) on Alfisols, ICRISAT, India. Bars show double pooled standard errors (Corlett. 1989).

sulted mainly from an above-ground interaction between canopies, as LER was unaffected by the root barrier. However, separation of the roots decreased millet yield because the volume of soil in the trench was very limited compared to the control intercrop where the millet roots were able to explore a larger soil volume. They suggested that below-ground interactions may be important in situations where below-ground resources, such as nutrients, limit plant growth.

A modified version of the root barrier technique was used to separate the below-ground interaction in alley cropping in semi-arid India, where the total dry matter of crops in the alleys was severely reduced by the presence of $L$. leucocephala. Parallel rows of L. leucocephala were grown in an Alfisol in a north south direction with a $3.3 \mathrm{~m}$ spacing between the hedgerows. During the rainy season, six rows of pearl millet were sown in the alleys, and the $L$. leucocephala was pruned to $0.7 \mathrm{~m}$ before millet sowing. Before the rainy season, a shallow root barrier was installed to a depth of $0.5 \mathrm{~m}$ on both sides of the $L$. leucocephala hedges which restricted the lateral roots in the horizontal horizons while allowing them to explore the soil fully below $0.5 \mathrm{~m}$. The four treatments consisted of sole millet $(\mathrm{SM})$, sole $L$. leucocephala $(\mathrm{SL})$, millet/ 


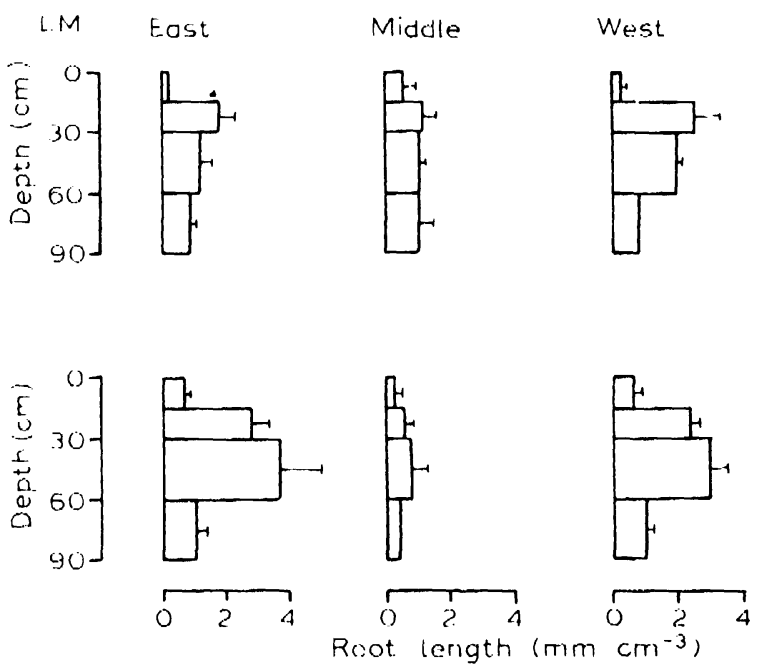

Fig. 4. Root length distribution of Lelucaena during the dry season 1987 in the LM and LMB alley cropping treatments on Alfisols, ICRISAT Center, India. Bars show standard errors (Corlall, 1989).

TABLI: 2

I)ry matter production of Leucaena on Alfisols, ICRISAT Center, 1986-1987 (Corlett, 1989)

\begin{tabular}{|c|c|c|c|}
\hline \multirow[t]{2}{*}{ Treatments } & \multicolumn{3}{|c|}{ Scasonal dry matter $\left(1 \mathrm{ha}^{-1}\right)$} \\
\hline & Rainy (Jun-Scp) & Postrainy (Sep-Jun) & Rainy \\
\hline Sole L. leucocephala (SL) & 4.01 & 1.50 & 7.14 \\
\hline Alley L. lencocephala (LM) & 3.11 & 2.17 & 5.63 \\
\hline $\begin{array}{l}\text { Alley } L \text {. lemeerephala with root } \\
\text { barrier (L.MB) }\end{array}$ & 3.12 & 3.28 & 6.27 \\
\hline $\mathrm{SF}:(t)$ & 0.56 & 0.26 & 0.46 \\
\hline$(\mathrm{V}(\%)$ & 27.4 & 20.6 & 12.5 \\
\hline
\end{tabular}

L. leucocephala alley cropping (LM) and LM with root barrier (LMB). In the $\mathrm{LM}$ treatment, the reduction in total dry matter by the production of millet was larger adjacent to the 2-year-old $L$. leucocephala hedges and overall reduction was $40 \%$ of SM (Fig. 2 ).

The root barrier virtually eliminated all the reduction in the dry matter production of millet. Competition between the pearl millet and $L$. leucocephala in the ML treatment began early in the season, even though significant differences only became apparent at $21 \mathrm{~d}$ after sowing (Fig. 3 ). In contrast, growth of millet seedlings in the LMB treatment was identical to that in the SM treatment. Excavation of the root system of $L$. leucocephala during the 


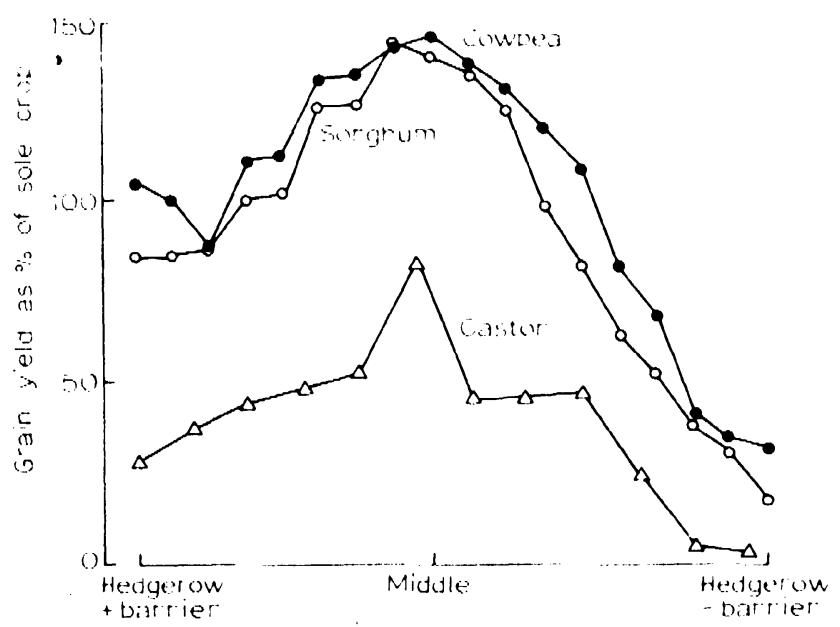

Fig. 5. Grain yield of sorghum, cowpea, and castor between L.thedena hedgerows on an Allisol. Hyderabad, India. A polythene root barrier was installed to a depth of $(1.5 \mathrm{~m}$ on the left-hand side of the alley (Singh et al.. 1989).

1987 dry season, 16 months after the barriers were installed, clearly showed that the roots were distributed throughout the alley, with the maximum root density being found in the top $30 \mathrm{~cm}$ in LM (Fig. 4). The root barrier had a marked effect on the root density in the top $30 \mathrm{~cm}$ and also displaced the largest root density down to $30-60 \mathrm{~cm}$. In addition, the root density in the middle of the alley was greatly reduced.

The presence of the root barrier appeared to have no adverse effect on the production of dry matter by the L. leucocephala (Table 2 ). Each produced about $3.1 \mathrm{tha}^{-1}$ from June to September and 2.2 to $3.3 \mathrm{tha}^{-1}$ from September to June of the following year. These observations are contrary to those reported by Willey and Reddy, who found that pearl millet suffered as a result of the root barrier, because in their barrier treatment the roots of millet were restricted down to $1 \mathrm{~m}$ (Willey and Reddy, 1981).

A similar approach to separate the below ground interaction was reported by Singh et al. (1989) who used a wider alley width $(10 \mathrm{~m})$ and taller hedgerows (3-4 m). In their study, the $L$. leucocephala was four years old and the adverse effects of competition had extended beyond $3 \mathrm{~m}$ in the alley (Fig. 5 ). In the experiment, three important dryland crops (sorghum, cowpea and castor) were grown in the alleys. Durations to maturity were $70 \mathrm{~d}$ for cowpea, 90 $\mathrm{d}$ for sorghum, and $150 \mathrm{~d}$ for castor. Competition from $L$. leucocephala was greater when crop duration increased. The root barrier was installed to $0.5 \mathrm{~m}$ as in the previous example. Similarly, the root barrier almost completely removed the adverse effect on both cowpea and sorghum, but only partly in castor. The shallower rooting cowpea and sorghum appeared to be protected 
from the prolific rooting of $L$. leucocephala. The yield in the middle of the alley was unexpectedly enhanced, possibly because of the residual benefit of a.hedgerow removed two years earlier. In addition to these observations, light temperature, humidity, and windspeed were measured by an automatic data logger. The results suggested that modification of microclimate is relatively unimportant compared to below ground competition (Singh et al., 1989).

\section{DISCUSSION}

The evidence assembled from these studies in semi-arid India is contrary to the key assumptions on the ecological benefits attributed to agroforestry. The minor improvement in microclimate associated with alley-cropping is perhaps not surprising, since temperature, humidity, and radiation during the rainy season are favorable to crop growth. In the humid tropics, the benefits arising from microclimatic modification is even less, and substantial improvements in crop yield in agroforestry systems were reported where tree prunings are used as mulch or as green manure (Kang et al., 1985). Mulching increases soil moisture retention, while burial of prunings improves decomosition of organic matter. A similar conclusion has been reached concerning he role of shade trees on coffee and cacao in Costa Rica, where water is rarely imiting but nutrient leaching is enhanced by heavy rains (Beer, 1988). Shade rees, such as Erythrina and Cordia, provided 50-100 $\mathrm{tha}^{-1}$ of litter but only $50 \mathrm{~kg} \mathrm{~N}$. The study concluded that litter production is more important than $\mathrm{N}$ fixation in the system.

The alley cropping practice recommended by Kang and his coworkers requires severe tree prunings to avoid shading the understory crops and expose them to $90 \%$ of the incident light. In a study of the effects of pruning intensities in alley cropping with maize and cowpea on Alfisol in Nigeria, shading reduced maize yield from $4.4 \mathrm{tha}^{-1}$ to $0.76 \mathrm{tha}^{-1}$ (Duguma et al., 1988), although no attempt was made to separate the effects arising from below ground interaction. In semi-arid India, it is also widely believed that shading by trees is responsible for poor yields of associated crops, although the evidence presented here clearly indicates that the real problem is competition for moisture. It should, however, be pointed out that alley cropping is a very sound technology for improving the fertility of degraded, low-activity clay soil in :..e tropics, and the key to its success is the use of tree prunings as green manure or mulch. In many regions of the arid and semi-arid tropics, farmers would have a more immediate use for such prunings as fodder, and hence little organic material is available for mulching before the onset of the rainy season. Even in the humid tropics, regular removal of prunings from alley crops may substantially reduce the yield of associated maize [from $1 \mathrm{t} \mathrm{ha}^{-1}$ to $0.26 \mathrm{tha}^{-1}$ in four years (Kang et al., 1985) ].

Are the present findings of adverse below-ground interactions in semi-arid 
India peculiar to L. lencocephala? It is true that agroforestry investigations in India are largely confined to L. leucocephala and alley cropping, but hundreds of experiments on other species have been initiated recently. An important step is to determine root distribution of important tree species and of the most appropriate companion crops. Such a study was carried out in Morogoro, Tanzania ( rainfall $870 \mathrm{~mm} \mathrm{a}^{-1}$ ) to describe the root profile of 5 important tree species (including $L$. leucocephala) and maize on unfertilized fields (Jonsson et al., 1988). They found that the root distribution of these trees and maize were similar, and more importantly, that the trees had twice the density of fine roots as maize. This evidence suggests that competition for below-ground resources would naturally favor the trees, which corroborates the negative interactions reported here. It is necessary to note that the root distribution of isolated trees may not correspond with that in intimate mixture of trees and crops. For instance, studies on intercropping sorghum/pigeonpea at ICRISAT have shown that the presence of sorghum reduced the root density of the slower-growing pigeonpea in the top $15 \mathrm{~cm}$ of the soil profile (Chauhan, 1989).

Returning to the comparison of intercropping and agroforestry systems it is useful to discuss the main differences and develop a better strategy to reduce the negative interactions. The biggest difference lies in the strong competition between $L$. leucocephala and associated crops during the early part of the growing season. It is suggested that the use of a tree species or a management regime which encourages slow regrowth of the tree component is desirable. This behavior is comparable to the initial slow-growing trait of pigeonpea. an ideal intercrop species. At ICRISAT, this trait is being exploited in research on the role of perennial pigeonpea as an agroforestry species. Preliminary results indicate that it provides the same grain yield and intercropping advantage ( LER $=1.5$ ) as conventional pigeonpea (Daniel and Ong, 1990 ), but it also yields a dry-season fodder of 2-5 $\mathrm{tha}^{-1}$ on Alfisol, comparable to L. leucocephala (Ong, 1991).

Another strategy is to use a very low population of widely dispersed trees amongst crops. The potential drawback of such a system might be that it would be unable to utilize a large fraction of the below-ground resources. Our studies with perennial pigeonpea have shown that a high population of perennial pigeonpea can explore much deeper horizons of the soil during the dry season than conventional pigeonpea, thereby providing greater utilization of resources, and yet no negative interaction with associated crops like sorghum and groundnut was evident. The prospects for physical and chemical soil improvements offered by agroforestry in the SAT are largely unknown, although work at ICRISAT and elsewhere in India continues to concentrate on this area of research. 


\section{REFERENCES}

Beer. J., 1988. Litter production and nutrient cycling in coffec ( Coffeca arabica) or cacao (Theo)broma (acal) ) plantations with shade trees. Agrofor. Syst., 6: 103-114.

Chauhan. Y.S., 1989. The root system of pigconpea. In: M.A. Salam and P.A. Wahid (Editors), The Rooting Patterns of Tropical Crops (in press).

Corlett, J.E., 1989. Leucaena/millet alley cropping in India: Microclimate and productivity. Ph.D. Thesis, University of Nottingham.

Corlett. J.E.,Ong. C.K. and Black, C.R., 1987. Microclimatic modifications in intercropping and alley cropping systems. In: W.S. Reifsnyder and T.O. Darnhofer (Editors), Meteorology and Agroforestry. ICRAF, Nairobi, Kenya, pp. 419-430.

Daniel, J.N. and Ong, C.K., 1990. Perennial pigeonpea: A multipurpose species for agroforestry. Agrofor. Syst., 10: 113-129.

Duguma, B., Kang, B.T. and Okali, D.U.U., 1988. Effect of pruning intensities of three woody leguminous species grown in alley cropping with maize and cowpea on an Alfisol. Agrofor. Syst., 6: 19-35.

Huxley, P.A. 1983. Some characteristics of trees to be considered in agroforestry. In: P.A. Huxley (Editor). Plant Research and Agroforestry. IC:RAF, Nairobi, Kenya, pp. 3-12.

Jonsson, K., Fidjeland, L., Maghembe, J.A. and Hogberg, P., 1988. The vertical distribution of fine roots of five tree species and maize in Morogoro. Tanzania. Agrofor. Syst., 6: 63-70.

Kang. B.T., Grimme, H. and Lawson, T.L., 1985. Alley cropping sequentially cropped maize and cowpea with Le'ucaena on a sandy soil in southern Nigeria. Plant Soil, 85: 267-277.

Marshall, B. and Willey, R.W.. 1983. Radiation interception and growth in an intercrop of pearl millet/groundnut. Ficld Crops Res., 7: 141-160.

Monteith, J.L., Ong, C.K. and Corlett, J.E., 1991. Microclimatic interactions in agroforestry systems. For. Ecol. Manage., 45: 31-44.

Natarajan, M. and Willey, R.W., 1980. Sorghum-pigeonpea intercropping and the effects of plant population density. II. Resource use. J. Agric. Sci. Camb., 95: 59-65.

Nelliat, E.V.. Bavappa, K.V. and Nair, P.K.K., 1974. Multi-storyed cropping - A new dimension in multiple cropping for coconut plantations. World Crops, 26: 262-266.

Ong. C.K., 1991. Interactions of light, water and nutrients in agroforestry systems. In: M.E. Avery, M.G.K. Cannell and C.K. Ong (Editors), Biophysical Rescarch for Asian Agroforestry. Winrock International, New Delhi, pp. 107-124.

Sandford, S., 1989. Crop residue/livestock relationship. In: Workshop on Soil, Water and Crop Livestock Management Systems for Rainfed Agriculture in the Sudano-Sahelian Zone, Niamey, 11-17 Jan 1987.

Singh, R.P., Ong, C.K. and Saharan, N., 1989. Microclimate and growth of sorghum and cowpea in alley cropping in semi-arid India. Agrofor. Syst., 9: 259-274.

Singh, R.P., Van den Beldt, R.J., Hocking, D. and Korwar, G.R., 1986. Alley farming in the semi-arid regions of India. Paper presented at the Alley Farming Workshop, March 1986, IITA, Ibadan, Nigeria.

Stirling, (.M., 1988. Environmental effects on partitioning and development in groundnut. Ph.D). Thesis, University of Nottingham.

Wiersum, K.F., 1984. Surface erosion under various tropical agroforestry systems. In: C.L. O'Loughlin and A.J. Pearce (Editors), Symposium on Effects of Forest Land Use on Erosion and Slope Stability. Environment and Policy Institute, East-West Center, Honolulu, Hawaii, USA, pp. 231-239.

Willey. R.W., 1979. Intercropping - Its importance and research needs. I. Competition and yield advantages. Field Crop Abstr., 32:1-10.

Willey, R.W. and Reddy, M.S., 1981. A field technique for separating above and below ground 
interactions in intercropping: An experiment with pearl millet/groundnut. Exp. Agric.. 17: 257-264.

Willey. R.W., Reddy, M.S. and Natarajan. M., 1987. Conventional cropping systems for Altisols and some implications for agroforestry systems. In: Procedings of the (onsultants Workshop on the State of the Art and Management Alternatives for Optimising the Productivity of SAT Alfisols and Related Soils, 1-3 December 1983. IC RISAT (enter. India.

Young. A.. 1986. The potential of agroforestry for soil conservation. I. Erosion control. IC RAY Working Paper 42, Nairobi, $68 \mathrm{pp}$. 